\title{
Research on the Mechanism of Power Supply Interruption Risk for Important User Based on Interpretative Structural Model
}

\author{
Wei Dong, Cunbin Li, Jiahang Yuan \\ School of Economics and Management, North China Electric Power University, Beijing, China \\ Email: yuanjiahang@126.com
}

How to cite this paper: Dong, W., Li, C.B. and Yuan, J.H. (2017) Research on the Mechanism of Power Supply Interruption Risk for Important User Based on Interpretative Structural Model. Journal of Service Science and Management, 10, 537-546. https://doi.org/10.4236/jssm.2017.106041

Received: November 3, 2017

Accepted: December 19, 2017

Published: December 22, 2017

Copyright (c) 2017 by authors and Scientific Research Publishing Inc. This work is licensed under the Creative Commons Attribution International License (CC BY 4.0). http://creativecommons.org/licenses/by/4.0/

\begin{abstract}
In order to effectively manage the safety risk for power supply to important power user, and increase power supply safety and reliability, interpretative structural model is used to explore the generation mechanism of power supply \& utility system safety risk and the risk element transfer path. Based on analysis of risk element, interpretative structural model of power supply risk generation mechanism is constructed. This model analyzes the hierarchical relationship between each risk element and transmission path, and then reveals the power safety risk generation mechanism, identifies the key risk element to be supervised by power supply companies \& users, and helps the power supply and utility company to improve the power safety management.
\end{abstract}

\section{Keywords}

Important Power User, Power Supply Safety, Risk Element, Generation Mechanism, Transfer Path

\section{Introduction}

With rapid development of society and smart grid, the requirement from power user for safety power supply is getting higher and higher. Important power user refers to those power utility units which are highly important from social, political or economic perspective, any breakdown of power supply to those units may cause personal injury, severe environment pollution, significant political disturbance, huge economic loss, or social public disorder; or any power utility unit which has special requirement for the power supplier reliability [1] [2]. Important power user plays a very important role in society, acting as key momentum of economy growth or lifeline of the cities. Power outage to important power 
user can result in chain events, causing huge economic loss to country and users, even personal injury. The request for a safety power supply is getting higher, and on the other hand the power supply and distribution system is becoming more and more complicated because the grid intellectual and automatic level has increased due to the smart grid development. So how to fully and effectively control and manage power supply risk to important power user has become a critical issue to power supply companies.

A lot of studies have been done by domestic researchers regarding power supply risk. Lu has a lot of study findings about large power grid stabilization by setting up a power system chain event breakdown and power outage simulation model [3] [4] [5]; Zhang studies how to reduce the power safety risk by improving user side facility management [6] [7]; Liu suggests power supply companies to strengthen power usage safety inspection and user's electricity danger management, in order to supervise the end user power consumption activity, which will reduce power supply risk [8] [9] [10] [11]; Some documentaries propose to reduce power transmission equipment risk by reasonably evaluating equipment conditions to implement the power transmission equipment management. And there are also some researchers to start the study from power supply risk mitigation strategy perspective, and bring up some risk mitigation actions for risk such power outage [12] [13]. Overseas researchers also conducted a lot of studies, mainly focusing on grid side power supply and utility stabilization. For example Lee, C.-H., Hsieh gives out suggestions to increase grid side power supply reliability by analyzing the reason and course of power outage. There are also quite some research achievements regarding the management of other risk element. Take emergency control risk as an example, Jeff Brown analyzes the damage to hospital operation because of power supply stop in US power outage event, and gives his suggestion regarding how to control element control risk as well as the emergency equipment configuration. In addition, some researchers focus on quantization of economic loss caused by power supply loss.

From above, we can find that the study of power supply risk control has mainly focused on power grid side. The analysis of power supply risk on user side is rare, always limited to risk identification and evaluation, which separately studies the influence and control of each risk element, not to analyze inter-influence and restriction among risk elements from system dynamic point of view. In this way, it is difficult to explain the hierarchy and relationship of the risk elements, and also difficult to explain the risk generation mechanism [14]. This paper will use interpretative structural model to study the generation mechanism of power supply interruption risk to important power user, to study the influence of each risk element to power supply safety, which will create a basis to important user power safety risk prevention and control.

\section{Important User Power Outage Risk Element Identification}

By checking the important user power outage event log and important user 
safety hazard details recorded by one provincial power supply company, and combining the important user power supply risk element identification studies done by overseas \& demotic researchers, we think the risk elements which may affect power supply safety to important user can be categorized into below 17 items: power grid supply risk, distribution network structure risk, power grid operation stabilization risk, internal power supply risk, equipment fault risk, equipment quality risk, user's own backup battery risk, emergency control risk, contingency plan management risk, daily management risk, user equipment maintenance risk, safety tools management risk, electrical engineer management risk, power utility safety inspection risk, regulation and safety measure management risk, man-made accident risk, natural environmental risk.

These 17 risks are not isolated. They influence and restrict each other, jointly affect the power supply and utility activity. With so many risks identified, it is difficult to figure out the power supply safety risk generation mechanism, and also difficult to judge the dangerous level of each risk element, which is the reason why power supply companies feel hard to set up effective supervision to control the main risk element. This paper will set up an interpretative structural model of power supply interruption risk, in order to analyze the risk generation mechanism.

\section{Risk Generation Mechanism}

Interpretative structural model was introduced in 1973, trying to solve complicated social economy system problem. It can describe how risk elements affect each other with a hierarchy structural model, by breaking down a complicated system, analyzing the direct dependence and relationship among each element. Using interpretative structural model, it is possible to convert a relationship sophisticated event into a clearly structured model, which is especially suitable for system analysis with multiple variables, sophisticated relationship and fuzzy structure [14] [15].

The steps of setting up an interpretative structural model as following:

1) Set up a adjacency matrix

By analyzing the relationship between each complicated element in the system with support from industry expert, it is possible to confirm the logical relationship between each risk element and then set up an adjacency matrix of each element, called adjacency Matrix $A$. In this matrix, element $a_{i j}$ refers to the relationship between element $C_{i}$ and $C_{j}$, i.e.

$$
a_{i j}=\left\{\begin{array}{l}
1, C_{i} \text { and } C_{j} \text { are related } \\
0, C_{i} \text { and } C_{j} \text { are not realated }
\end{array}\right.
$$

Setting parameters as below: $C_{1}$ means overall power supply interruption risk to important user, $C_{2}$ means power grid supply risk, $C_{3}$ means distribution network structure risk, $C_{4}$ means power grid operation stabilization risk, $C_{5}$ means internal power supply risk, $C_{6}$ means equipment fault risk, $C_{7}$ means equipment quality risk, $C_{8}$ means users own backup battery risk, $C_{9}$ means emergency con- 
trol risk, $C_{10}$ means contingency plan management risk, $C_{11}$ means daily management risk, $C_{12}$ means user equipment maintenance risk, $C_{13}$ means safety tools management risk, $C_{14}$ means electrical engineer management risk, $C_{15}$ means power utility safety inspection risk, $C_{16}$ means regulation and safety measure management risk, $C_{17}$ means man-made accident risk, $C_{18}$ means natural environmental risk. Adjacency $A$ is set up as below:

$$
A=\left(\begin{array}{llllllllllllllllll}
0 & 0 & 0 & 0 & 0 & 0 & 0 & 0 & 0 & 0 & 0 & 0 & 0 & 0 & 0 & 0 & 0 & 0 \\
1 & 0 & 0 & 0 & 0 & 0 & 0 & 0 & 0 & 0 & 0 & 0 & 0 & 0 & 0 & 0 & 0 & 0 \\
0 & 0 & 0 & 0 & 1 & 0 & 0 & 0 & 0 & 0 & 0 & 0 & 0 & 0 & 0 & 0 & 0 & 0 \\
0 & 1 & 0 & 0 & 0 & 0 & 0 & 0 & 0 & 0 & 0 & 0 & 0 & 0 & 0 & 0 & 0 & 0 \\
1 & 0 & 0 & 0 & 0 & 0 & 0 & 0 & 0 & 0 & 0 & 0 & 0 & 0 & 0 & 0 & 0 & 0 \\
0 & 0 & 0 & 0 & 1 & 0 & 0 & 0 & 0 & 0 & 0 & 0 & 0 & 0 & 0 & 0 & 0 & 0 \\
0 & 0 & 0 & 0 & 1 & 1 & 0 & 0 & 0 & 0 & 0 & 0 & 0 & 0 & 0 & 0 & 0 & 0 \\
0 & 0 & 0 & 0 & 0 & 0 & 1 & 0 & 0 & 0 & 0 & 0 & 0 & 0 & 0 & 0 & 0 & 0 \\
1 & 0 & 0 & 0 & 0 & 0 & 0 & 0 & 0 & 0 & 0 & 0 & 0 & 0 & 0 & 0 & 0 & 0 \\
0 & 0 & 0 & 0 & 0 & 0 & 1 & 0 & 0 & 0 & 0 & 0 & 0 & 0 & 0 & 0 & 0 & 0 \\
0 & 0 & 0 & 0 & 1 & 1 & 0 & 1 & 0 & 0 & 0 & 0 & 0 & 0 & 0 & 0 & 0 & 0 \\
0 & 0 & 0 & 0 & 0 & 0 & 0 & 0 & 0 & 0 & 1 & 0 & 0 & 0 & 0 & 0 & 0 & 0 \\
0 & 0 & 0 & 0 & 0 & 0 & 0 & 0 & 0 & 0 & 1 & 0 & 0 & 0 & 0 & 0 & 0 & 0 \\
0 & 0 & 0 & 0 & 0 & 0 & 0 & 0 & 0 & 0 & 1 & 0 & 0 & 0 & 0 & 0 & 0 & 0 \\
0 & 0 & 0 & 0 & 0 & 0 & 0 & 1 & 0 & 1 & 0 & 0 & 0 & 0 & 0 & 0 & 0 & 0 \\
0 & 0 & 0 & 0 & 0 & 0 & 0 & 0 & 0 & 0 & 1 & 0 & 0 & 0 & 0 & 0 & 0 & 0 \\
0 & 1 & 0 & 0 & 1 & 0 & 0 & 0 & 0 & 0 & 0 & 0 & 0 & 0 & 0 & 0 & 0 & 0 \\
1 & 0 & 0 & 0 & 0 & 0 & 0 & 0 & 0 & 0 & 0 & 0 & 0 & 0 & 0 & 0 & 0 & 0
\end{array}\right)
$$

\section{2) Calculate reachable Matrix $R$}

From adjacency matrix to calculate reachable matrix. Based on adjacency Matrix $A$, to calculate the power operation of matrix until below equation is achieved:

$$
A_{i}=(A+I)^{i}, 1 \leq i \leq n-1
$$

Boolean operation rule $(0+0=0,0+1=1,1+0=1,1+1=1,0 \times 0,0 \times 1=$ $0,1 \times 0=0,1 \times 1=1)$ is applied in above power operation. By doing so we can get below:

$$
A_{1} \neq A_{2} \neq \cdots \neq A_{r-1}=A_{r}, r \leq n-1
$$

In above, $n$ refers to matrix order. So reachable matrix $R=A_{r-1}=(A+I)^{r-1}$ can be worked out. Below is the reachable matrix calculated from actual data: 


$$
R=\left(\begin{array}{llllllllllllllllll}
0 & 0 & 0 & 0 & 0 & 0 & 0 & 0 & 0 & 0 & 0 & 0 & 0 & 0 & 0 & 0 & 0 & 0 \\
1 & 1 & 0 & 0 & 0 & 0 & 0 & 0 & 0 & 0 & 0 & 0 & 0 & 0 & 0 & 0 & 0 & 0 \\
1 & 0 & 1 & 0 & 1 & 0 & 0 & 0 & 0 & 0 & 0 & 0 & 0 & 0 & 0 & 0 & 0 & 0 \\
1 & 1 & 0 & 1 & 0 & 0 & 0 & 0 & 0 & 0 & 0 & 0 & 0 & 0 & 0 & 0 & 0 & 0 \\
1 & 0 & 0 & 0 & 1 & 0 & 0 & 0 & 0 & 0 & 0 & 0 & 0 & 0 & 0 & 0 & 0 & 0 \\
1 & 0 & 0 & 0 & 1 & 1 & 0 & 0 & 0 & 0 & 0 & 0 & 0 & 0 & 0 & 0 & 0 & 0 \\
1 & 0 & 0 & 0 & 1 & 1 & 1 & 0 & 0 & 0 & 0 & 0 & 0 & 0 & 0 & 0 & 0 & 0 \\
1 & 0 & 0 & 0 & 0 & 0 & 0 & 1 & 1 & 0 & 0 & 0 & 0 & 0 & 0 & 0 & 0 & 0 \\
1 & 0 & 0 & 0 & 0 & 0 & 0 & 0 & 1 & 0 & 0 & 0 & 0 & 0 & 0 & 0 & 0 & 0 \\
1 & 0 & 0 & 0 & 0 & 0 & 0 & 0 & 1 & 1 & 0 & 0 & 0 & 0 & 0 & 0 & 0 & 0 \\
1 & 0 & 0 & 1 & 1 & 0 & 1 & 1 & 0 & 1 & 0 & 0 & 0 & 0 & 0 & 0 & 0 \\
1 & 0 & 0 & 0 & 0 & 0 & 0 & 1 & 1 & 0 & 1 & 1 & 0 & 0 & 0 & 0 & 0 & 0 \\
1 & 0 & 0 & 0 & 1 & 1 & 0 & 1 & 1 & 0 & 1 & 0 & 1 & 0 & 0 & 0 & 0 & 0 \\
1 & 0 & 0 & 0 & 1 & 1 & 0 & 1 & 1 & 0 & 1 & 0 & 0 & 1 & 0 & 0 & 0 & 0 \\
1 & 0 & 0 & 0 & 0 & 0 & 0 & 1 & 1 & 1 & 0 & 0 & 0 & 0 & 1 & 0 & 0 & 0 \\
1 & 0 & 0 & 0 & 0 & 0 & 0 & 0 & 0 & 0 & 0 & 0 & 0 & 0 & 0 & 0 & 0 & 1
\end{array}\right)
$$

Assume we define level 0 element as empty set, i.e. $L_{0}=\varnothing$, we can group the system elements into different groups using hierarchical iterative algorithm as below:

$$
L_{k}=\left\{C_{i} \in C-L_{0}-\cdots-L_{k-1} \mid R_{k-1}\left(C_{i}\right) \cap A_{k-1}\left(C_{i}\right)=R_{k-1}\left(C_{i}\right)\right\}
$$

In which: $R_{k-1}\left(C_{i}\right)$ is a reachable set calculated from a subgraph which contains element of $C_{i} \in C-L_{0}-\cdots-L_{k-1}$, while $A_{k-1}\left(C_{i}\right)$ is a antecedent set calculated from a subgraph which contains element of $C_{i} \in C-L_{0}-\cdots-L_{k-1}$ [14]. According to the hierarchical iterative algorithm shown in Equation (6), we can group the elements of level 1 to 5 as below:

$$
[1 ; 2,5,9,18 ; 3,4,6,8,10,17 ; 7,11,15 ; 12,13,14,16]
$$

3) Compute backbone matrix

By working out a backbone Matrix $M$ and combining above grouping result, a system element structure model can be built. If reachable Matrix $R$ is the reduced matrix of system, it means that system backbone Matrix $M$ uniquely exists, as below:

$$
M=R-I-(R-I)^{2}
$$




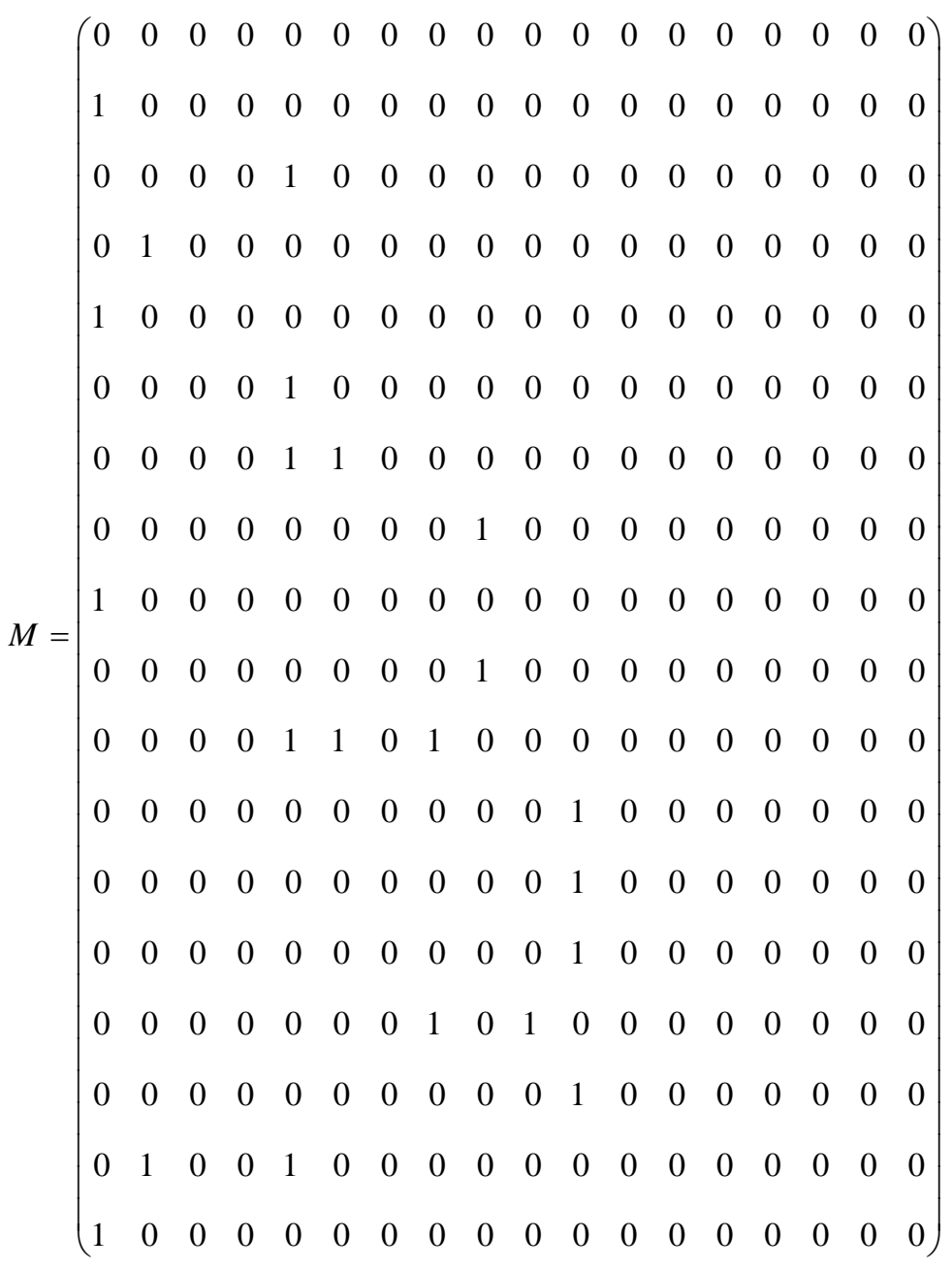

4) Set up system structure model

Based on above grouping result achieved and minimal edger reachable Matrix $M$, the interpretative structure model of important user power supply interruption risk generation mechanism is built shown in Figure 1.

\section{The Analysis of Power Supply Interruption Risk Generation Mechanism to Important User}

From above analysis and interpretative structure model built, we can clearly find the mechanism of important user power supply interruption risk, in which the risks are basically grouped into 5 levels as below:

The first level is overall power supply interruption risk to important user. This risk will directly affect the normal operation of important users, directly causing severe economic loss or personal injury, even damage the social stabilization.

The second level is the direct performance factors of important power supply interruption risk, including power grid supply risk, internal power supply risk, emergency control risk and natural environmental risk. Power grid supply risk and internal power supply risk will affect the power transmission from external and internal perspective, the lost of either will cause power supply accident to 


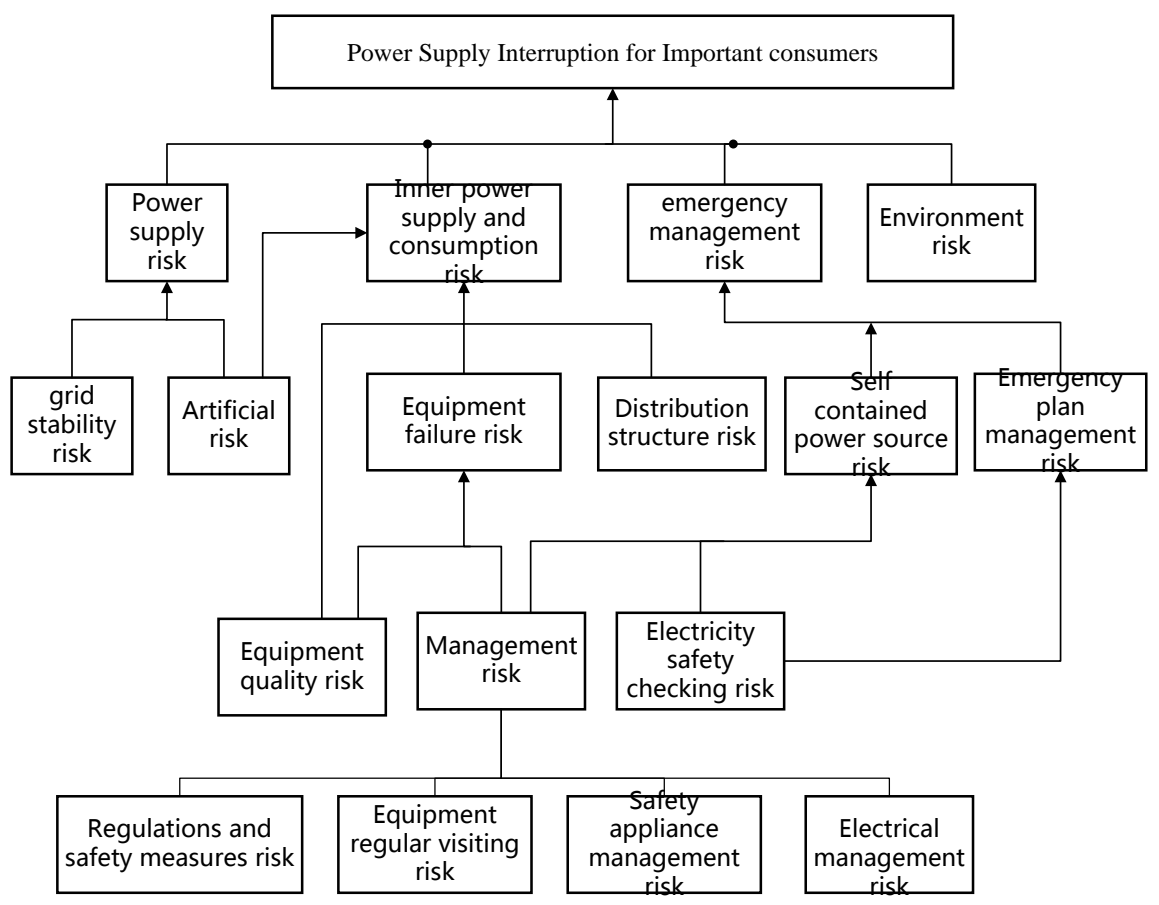

Figure 1. The mechanism of power supply interruption risk for important user based on interpretative structural model.

users. Natural environmental risk means force majeure occurred in nature will damage the power supply equipment. Emergency control risk means if reasonable solution and emergency equipment are placed when power supply breakdown happens, the loss caused by power outage can be reduced.

The third level includes power grid operation stabilization risk, man-made accident risk, equipment fault risk, distribution network structure risk, user's own backup battery risk, contingency plan management risk. Power grid operation stabilization risk concerns the stabilization of main power supply grid, which is the source of power energy and will directly affect the successful power supply. Man-made accident risk means damage to power supply facility caused by human activities, which directly affect the risk at both power grid supply side and user side. Equipment fault risk and distribution network structure risk will directly affect user internal power supply and consumption risk, so it is needed to control the equipment fault rate within reasonable level and properly configure distribution network structure in order to increase its reliability. User's own backup battery risk and contingency plan management risk can affect emergency control risk, as power supply interruption risk can be reduced if user installs reasonable backup battery, while emergency control risk can be reduced if corresponding contingency plan are prepared.

The fourth level includes equipment quality risk, daily management risk and power utility safety inspection risk. Equipment quality risk refers to equipment manufacturing qualify and latent defect, which will cause equipment breakdown risk. Daily management risk refers to whether the user periodically check and 
maintain electric equipment, as planned routine maintenance can quickly find out any equipment operation danger, which will reduce equipment breakdown risk and increase backup battery reliability. Power utility safety inspection risk refers to quarterly electricity safety inspection conducted by power supply companies at user site, a careful electricity safety inspection can help the user to find out most of the electricity danger in daily operation, mainly focusing on the inspection to own backup battery and contingency plan.

The fifth level are basic risk elements in user's daily management, including regulation and safety measurement management risk, equipment routine maintenance risk, safety tools management risk, electrical engineer management risk. Regulation and safety measurement management risk refers to if user has set up effective regulation regarding power distribution room operation, including high voltage distribution room operation regulation, high voltage transfer switch operation regulation, high voltage distribution room fire prevention regulation, high voltage distribution room general regulation, high voltage distribution room operator responsibility description, high voltage distribution room on duty shifting rule, distribution room firing distinguish system management etc. Equipment routine maintenance risk refers to power user's electric equipment annual maintenance plan and execution. Safety tools management risk refers to the deployment of electrical safety tools at user's site, such as electroprobe, grounding connection line. Electrical engineer management risk refers to the employment of electrician, the qualification of electrician and on job training provided.

From above interpretative structural model, it clearly demonstrates the power supply interruption risk generation mechanism, and the transfer path of each risk element. By rational analysis and control of transfer path between each risk element, it can supervise related risk element selectively, so as to provide guarantee a safe power supply to important user.

\section{Conclusions}

From analysis above, we can conclude that, the basic risk elements which may affect power supply reliability to important user are various. In order to guarantee a safe power supply to important user, it requires the coordination between multiple parties such as power supply companies, power users etc. Power grid stabilization control needs the joint effort from power supply company marketing department and maintenance department etc., in order to guarantee the stabilization from power grid side. Man-made accident risk is a risk which causes increasing accidents, also is a risk difficult to be controlled. Power supply companies should set up appropriate protection signs to propagate power transmission equipment protection awareness to public; and citizens should avoid unconscious damage to power supply facilities. Equipment quality risk needs joint effort from manufacture for an increased production standard and from quality control committee for high level supervision, in order to guarantee the quality of power supply equipment. Electricity safety inspection at user's site requires the 
power supply company to periodically conduct safety inspection, in order to eliminate any potential danger at early stage. Regarding to the power user's daily management risk, it needs user's corresponding department to set up a complete electricity operation manual, to mitigate all the listed risk; also it requests on time equipment maintenance, periodical tools calibration and planning on job training to electricians.

Focusing on the study of interpretative structural model of important user power supply interruption risk generation mechanism, this paper has analyzed the relationship hierarchy between each risk element and its transfer path, which further demonstrates the power supply interruption risk generation mechanism, identifies the key risk element which needs close supervision from each party who involved in power transmission activities. All these will provide a theory foundation to power supply companies and power users for power supply safety management.

\section{Acknowledgements}

The authors would like to acknowledge the supports from National Natural Science Foundation of China (No. 71271084, No. 71671065) and the technology project of State Grid (5204BB1600CN).

\section{References}

[1] Wei, Y. (2015) Discussion of Power Supply Management for High Risk and Important Electricity Users. Heilongjiang Science Information, No. 34, 109-109.

[2] Xu, A.Y. (2014) Important User Power Supply Status Analysis and Suggestions. Power Distribution and Utilization, No. 6, 18-21.

[3] Ye, X., Lu, Z.X., Qiao, Y., Li, J., Wang, F. and Luo, W. (2012) Large Scale Discussion on China Accidents of Wind Power Generator Trip. Power Automation, No. 8, 11-17.

[4] Yue, X.L., Wang, T., Gu, X.P., Li, K., Zhang, S. and Wang, T.Q. (2016) Identification of Weak Power Transmission lines Based on Self-Organized Criticality Theory. Power System Control \& Protection, No. 15, 18-26.

[5] Yang, F.Y., Dui, X.W., Tang, J.X. and Lu, Z.X. (2013) Reliability Evaluation of 500 $\mathrm{kV}$ Terminal Station Considering Station-Grid Coordination. Power System Technology, No. 3, 847-854.

[6] Zhang, Z.Z. (2011) Strengthen the Management of Power Supply to High Risk and Important Users. Automation Application, No. 12, 51-52.

[7] Li, W.P. (2014) Discussion of Power Supply \& Utility Safety Management and Risk Prevention. Countryside Electrician, No. 1, 6-6.

[8] Chen, J.X. (2016) Discussion of Important User Power Utility Safety and Potential Hazard Controlling. Communication World, No. 17, 171-172.

[9] Liu, Q.B. (2014) Discussion of Safety Checking and Potential Hazard Controlling of Power Supply to High Risk \& Important Users. China New Technology Enterprise, No. 30, 165-166.

[10] Cui, J.P. (2015) The Safety Hazard and Its Controlling of Power Supply to High Risk \& Important Users. China New Technology Enterprise, No. 36, 137-138. 
[11] Li, Y.H. and Chen, F. (2014) Safety Inspection Practice of Power Supply to High Risk \& Important Users and Analysis of Hazard Control. China New Technology \& Product, No. 4, 168-169.

[12] Zhang, X.S. (2014) The Application of Equipment Status Risk Evaluation in Important User Power Supply Management. Motor Information, No. 30, 172-173.

[13] Yin, H. and Ci, X.Y. (2010) Power Supply Safety Service Risk and Its Prevention. China Power Enterprise Management, No. 29, 64-65.

[14] Yang, B., Yu, B. and Sun, Q. (2010) Overseas Oil \& Gas Development Project Risk Generation Mechanism Based on Interpretative Structural Model. Journal of Haerbin Engineering University, 31, 1259-1264.

[15] Shi, Y.P. (2011) Discussion of Safety Service of Power Supply to High Risk \& Important User. Entrepreneur World, No. 11, 54-54. 